\title{
Revisão dos conceitos sobre a evolução bípede e aplicação na Fisioterapia
}

\author{
Revision of the concepts about biped evolution with application in the \\ physical therapy
}

\section{Eliana Maria Varise ${ }^{1}$, Sissy Veloso Fontes², Márcia Maiumi Fukujima ${ }^{3}$, Gilmar Fernandes do Prado ${ }^{4}$}

\section{RESUMO}

Foi realizada uma revisão da literatura para a apresentação dos dados que correlacionam os mecanismos da seleção natural para a evolução da marcha bípede e as estratégias utilizadas pelos fisioterapeutas para a recuperação parcial ou total dos pacientes. Um longo caminho foi percorrido pelos seres vivos para o estabelecimento das suas características anatômicas e comportamentais. Há milhões de anos, para a espécie humana sobreviver nos mais diversos e adversos ambientes, os sistemas neural e musculosquelético passaram por modificações e os diferentes desafios promoveram enorme sofisticação motora que também se exprime no âmbito da cognição e da comunicação, pautando, inclusive, as relações afetivas e sociais. Este tão refinado sistema motor apresentase freqüentemente perturbado por afecções limitantes. Dentre suas atribuições específicas, a fisioterapia pode recuperar a independência funcional, total ou parcialmente, agregando suas ferramentas de trabalho às estratégias de modificação ambiental e às múltiplas tarefas proposicionais comuns do cotidiano, na tentativa de recrutar o controle do corpo na postura bípede a capacidade de deambular e, ao mesmo tempo, solucionar problemas.

Unitermos. Marcha, Fisioterapia, Evolução.

Citação. Varise EM, Fontes SV, Fukujima MM, Prado GF. Revisão dos conceitos sobre a evolução bípede e aplicação na Fisioterapia.

Trabalho realizado Universidade Federal de São Paulo, São Paulo-SP, Brasil.

1.Fisioterapeuta, Pós-graduanda da Universidade Federal de São Paulo - UNIFESP, Professora da UNINOVE, São Paulo-SP, Brasil.

2.Fisioterapeuta, Doutora pela UNIFESP, São Paulo-SP, Brasil.

3.Neurologista, Doutora, médica do Pronto Socorro de Neurologia da UNIFESP, São Paulo-SP, Brasil.

4.Neurologista, Doutor, Professor Adjunto da UNIFESP, São Paulo-SP, Brasil.

\section{SUMMARY}

A literature review was carried out and the data related to the correlations between natural selection strategies of the species and the fundaments used by physiotherapy for the acquirement and evolution of biped march was presented. Human beings ran a long path in order to establish their anatomical and behavioral characteristics. Millions of years ago, human beings in order to survive to the most different and hard environments, the neural and musculoskeletal systems went through changes and the different challenges promoted great motor improvement that is also shown within the sphere of cognition and communication, including, further, the affective and social relations. Such refined motor system is frequently affected by very limiting disorders. Amongst its specific attributions, physiotherapy can recover functional independence, in whole or in part, aggregating its work tools to environmental changes strategies and to the several tasks commonly present at our daily routine, when attempting to place control of body under the biped posture in open and closed kinetic chains, to walk and, at the same time, be capable of solving problems.

Keywords. Gait, Physical Therapy, Evolution. Citation. Varise EM, Fontes SV, Fukujima MM, Prado GF. Revision of the concepts about biped evolution with application in the physical therapy.
Endereço para correspondência: Eliana M Varise R. Leandro Dupret, $488 / 163$ CEP 04025-012, São Paulo-SP, Brasil E-mail:emvarise@uol.com.br

Recebido em: 24/05/2007 Revisado em: 25/05/2007 a 15/05/2008

Aceito em: 16/05/2008

Conflito de interesses: não 


\section{INTRODUÇÃO}

As vantagens do indivíduo em simular mentalmente suas próprias ações antes de executá-las e antecipar as intenções dos predadores modificou a anatomia do antropóide, consolidou o bipedalismo como meio de locomoção e a habilidade manual para as tarefas de alcance, preensão e manipulação ${ }^{1-8}$.

Quando os homens, mulheres e crianças saudáveis são vítimas de lesão do sistema sensorial, motor ou cognitivo podem deixar de se locomover ou de associar à deambulação ações simultâneas como: manter a conversação, manter a atenção em tarefas diárias ou localizar um alvo no ambiente, manipular ou transportar objetos. Assim, procuram meios para adquirir a independência funcional, pois a necessidade da assistência resulta na baixa auto-estima dos indivíduos incapacitados e sobrecarrega o cotidiano dos cuidadores $^{9,10}$.

A reabilitação pode proporcionar aos indivíduos acometidos o resgate da independência almejada, pela recuperação funcional e a adaptação frente às incapacidades provocadas por uma lesão. As atividades fisioterapêuticas destinam-se ao aperfeiçoamento do controle postural bípede e da marcha sem dispositivos auxiliares, quando possível, para associar ao ato da locomoção, tarefas que requeiram maior ou menor concentração, e motivação para otimizar a produção de fatores de crescimento neuronais, o reaprendizado motor e possibilitar a cada indivíduo alcançar seu potencial $^{2,3,9-14}$.

O propósito desta revisão é correlacionar a evolução bípede do homem com os fundamentos utilizados pela fisioterapia para o reaprendizado locomotor associado às ações proposicionais e discutir como esta correlação pode auxiliar na elaboração dos programas fisioterapêuticos para os pacientes com seqüelas decorrentes de afecções neurológicas e ou ortopédicas que resultam na redução da mobilidade e ou na necessidade de agregar dispositivos auxiliares para a marcha.

\section{O processo evolutivo dos seres humanos}

No Período do Devoniano, há cerca de 400 milhões de anos, os animais marinhos sofreram sucessivas transformações evolutivas e saíram do meio aquático para povoar a superfície terrestre, hipótese esta respaldada pelo achado dos fósseis de um tetrápode (Acanthostega) na Groenlândia com 360 milhões de anos ${ }^{1-3}$.

No Período Paleoceno, há cerca de $65 \mathrm{mi}$ Ihões de anos, diversas espécies animais e vegetais desapareceram como decorrência da catástrofe climática. A extinção dos dinossauros permitiu a disseminação dos mamíferos, principalmente um grupo de primatas que tinha hábitos noturnos $\mathrm{e}$ alimentação baseada em carniça ${ }^{2,15}$.

Cerca de 38 milhões de anos atrás, os símios ramificaram-se até o surgimento dos antecessores dos humanos e, a partir de 150 ou 100 mil anos, o homo sapiens, com características anatômicas modernas, estabeleceu-se como espécie dominante, iniciando a conquista da Terra ${ }^{2,3,16,17}$.

A grande capacidade de adaptação e o oportunismo dos primatas mobilizaram as estratégias para a caça em grupo, tornando-os mais cooperantes e altruístas na partilha dos alimentos. Desse modo, modelou-se um novo estilo de vida com a sofisticação da linguagem e da comunicação, para transmitir uns aos outros as intenções e os conhecimentos essenciais na luta pela sobrevivência ${ }^{2,6}$.

\section{O surgimento do bipedalimo na evolução humana}

Aristóteles, filósofo grego que viveu de 385 até 322 a.C., referia-se aos humanos como "bípedes sem asas" e ao ato de andar ereto como "o mais básico de todos os hábitos", sobretudo para contrastá-lo com aspectos nobres da singularidade humana, como a moral e a virtude ${ }^{18}$.

Um hábito, isto é, um comportamento regular, é determinado pela estrutura do organismo e pelo seu ambiente. Quaisquer causas estranhas ao comportamento, mas que afetem o organismo de forma hereditária poderá gerar modificações nesses hábitos. Essas mudanças produzidas pelas alterações no meio ambiente podem dar lugar às modificações orgânicas das quais algumas se transmitem à descendência ${ }^{19}$.

Nas interpretações da filogenia, com relação à estrutura anatômica geral, o bipedalismo é uma das características que separa os humanos das demais espécies. A partir de 1970, a datação radiométrica vem permitir modificações nas interpretações dos fósseis, proporcionando aos especialistas 
condições para concluir que os hominídeos se tornaram bípedes muito antes de serem inteligentes e antes mesmo do gênero Homo 2,15-17,20-22.

Com base na anatomia tradicional comparativa de Darwin, das provas paleontológicas e nos indícios recentes da biologia molecular, existem evidências das relações evolucionárias entre macacos antropóides, fósseis hominídeos e homens, em particular, o bipedalismo, desde quatro a sete milhões de anos 2 .

As suposições darwinianas (1871) sobre a origem e a finalidade hipotética da adaptação ao bipedalismo são baseadas no fato da postura vertical desocupar as mãos, a fim de possibilitar o uso de ferramentas. Mais tarde, Raymond Dart (1953) propôs que o bipedalismo teria sido adotado por ser vantajoso, possibilitar a vigia do território e facilitar o deslocamento entre as árvores na captura de insetos e outros alimentos que constituíam par-

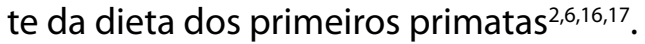

Em 1981, Owen Lovejoy publicou sua teoria sobre o bipedalismo, defendendo a idéia de que, quando os primatas foram confrontados com a tarefa de transportar demasiada comida, viram-se forçados a adotar uma postura vertical desajeitada e a utilizar as mãos para transportar maior quantidade de alimentos por longas distâncias. Assim, por meio da invenção de um recipiente, saco ou cesto primitivo, poderiam recolher os alimentos para dividi-los com os parentes mais próximos. Além disso, estariam despertando o interesse das fêmeas no aperfeiçoamento sexual, permitindoIhes manter os machos próximos por períodos mais longos, despendendo maior tempo de dedicação aos filhotes e garantindo a perpetuação da espécie num ambiente fragmentado $6,16,17$.

A teoria sobre a adoção da postura bípede atribuída a Robert Foley (2003) sustentou-se na ordem ecológica, ou seja, nas pressões seletivas e mudanças comportamentais para o homem encontrar alimento em ambiente adverso, com recursos escassos. Foley argumentou que os pequenos macacos se deslocavam entre as árvores de forma quadrúpede, enquanto os antropóides maiores realizavam esses deslocamentos na postura vertical. Quando ambos se viram forçados a viver no solo, levaram consigo sua bagagem evolucionária, ou seja, os quadrúpedes continuariam quadrúpedes, mas os antropóides, adaptados à postura vertical e à marcha sobre as juntas dos dedos das mãos, optariam pelo bipedalismo como o caminho mais provável para seu êxito terrestre 2 .

Para sustentar essa teoria, existe a comparação energética entre bípedes (hominídeos) e deambuladores sobre as juntas dos dedos das mãos (chipanzés). Esse estudo demonstra que, enquanto um chipanzé é capaz de percorrer onze quilômetros sobre as juntas dos dedos das mãos, um hominídeo, com o mesmo dispêndio de energia, poderia percorrer dezesseis quilômetros, demonstrando que o bipedalismo é, comprovadamente, mais eficiente ${ }^{17}$.

Os antropóides são muito apegados às árvores, por constituírem sua fonte de alimentação e proteção, porém, com a queda global da temperatura, o efeito sobre a África, paradoxalmente, tornou o ambiente mais seco, diminuiu a quantidade de árvores, tornando-as inóspitas, com poucos frutos e repletas de espinhos. Instalou-se o problema: uma vez que as árvores estavam pouco confortáveis para os seus habitantes, isso os levaria a passar a maior parte do tempo no solo, à procura de alimento. Conseqüentemente, a postura vertical seria adotada como mais uma estratégia comportamental vantajosa e funcional para o cotidiano, pois a superfície de contato, proporcionada pelo bipedalismo, diminuía em cerca de $60 \%$ o superaquecimento corporal ${ }^{2,17}$.

É preciso salientar que, na evolução, as transformações comportamentais tendem a preceder as grandes transformações anatômicas e pode-se esperar que o comportamento forneça as condições seletivas nas quais o hábito poderá imprimir as novas configurações anatômicas dos indivíduos que, selecionados, terão a possibilidade de continuarem evoluindo ${ }^{2,5,6}$.

Possivelmente, a frustração gerada pelo insucesso no transporte de grandes quantidades de alimentos despertou, no antropóide, um impulso reflexivo na tentativa de encontrar formas de evitar a exposição constante aos predadores e o desgaste energético e emocional, imposto pela tarefa sob um sol escaldante ${ }^{1-3}$.

No processo evolutivo, a seleção favorável do bipedalismo sugere que vários componentes se combinaram por motivos distintos em momentos diversos, ou seja, quando um antropóide, que já fazia algo, passou a fazê-lo com maior freqüência, pôde inserir um hábito no seu comportamento e, mais tarde, incorporá-lo à sua anatomia. Assim, Stanford reitera o que era afirmado por Aristóteles: 
"Nós somos o que repetidamente fazemos. Excelência, portanto, não é um ato, mas um hábito"6,17,18.

\section{As modificações morfológicas e funcio- nais do homem, atribuídas ao bipedalismo e ao processo de desertificação da África.}

Para caminhar e correr de maneira eficaz em ambiente aberto, perto do Equador e, ao mesmo tempo, subsidiar esse esforço e gasto energético, nossos ancestrais precisaram inserir uma dieta alimentar rica em proteínas e gorduras por meio do consumo da carne. Aponta-se esse fator associado ao desenvolvimento dos instintos sociais como grandes responsáveis pelo crescimento encefálico, que evoluiu de 320 e 380 centímetros cúbico (cc) até o homo sapiens atual, com medidas cranianas de $1400 c c$ até $2100 c^{8,16}$.

Um sistema eficiente de difusão de calor para prevenir o superaquecimento orgânico foi desenvolvido, e resultou numa pele desnuda de coloração predominantemente escura, devido à maior quantidade de melanina protegendo os indivíduos contra a ação nefasta dos raios ultravioleta ${ }^{16}$.

O alinhamento entre o crânio e a coluna proporcionou boa adaptação ao bipedalismo. No processo de aquisição da verticalização corporal e controle do tronco, os músculos glúteos, médio e mínimo, localizados exclusivamente na região posterior dos quadris, com a função de impulsionar os antropóides (músculos extensores), passaram anatomicamente para a região lateral. Dessa forma, assegurou-se a estabilidade dos quadris (músculos abdutores) na sustentação do corpo ereto, durante a marcha ${ }^{2,17}$.

Para consolidar a locomoção bípede, exigiuse um aperfeiçoamento do equilíbrio corporal, transformando o hálux e arcos plantares na plataforma flexível, que permite aos pés, adaptados à nova locomoção, absorver choques e tensões nas atividades de saltos. Andar sobre duas pernas ocasionou modificações na caixa de ressonância vocal, desvencilhou a necessidade da respiração ocorrer em sincronia com o passo, propiciando aos pulmões condições de modular a respiração para a evolução relacionada com a voz e a fala 3,6,16,17.

Com a caça, os primatas se tornaram mais destros, inteligentes e necessitados de armas e utensílios que compensassem a ausência de unhas afiadas, de grandes garras e de dentes que cortassem, permitindo a manipulação das novas ferramentas e a solução de problemas cada vez mais complexos $^{2,6}$.

\section{Um ser pensante: as habilidades cogniti- vas delineando os traços da civilização}

A consciência de um organismo deriva de seus sentidos e a ativação de um pensamento cada vez mais consciente atuaria como um sistema de estruturas cognitivas que organizam respostas a estímulos, despertando emoções que interagem com a razão. Os altos níveis de cognição implicam o uso do processo de pensamento para simular ações, com conseqüências encenadas sem gasto energético ou riscos envolvidos na ação real ${ }^{1,2,17-19}$.

A caça alterou os primatas profundamente, pois estes caçadores precisaram refinar seus instintos e desenvolver a capacidade de se concentrar por longos períodos, praticando mentalmente um projeto organizado e comunicando suas impressões aos demais integrantes do grupo. Essa atenção prolongada para entender a ação dos outros e a capacidade de organizar-se socialmente foi determinante para a sobrevivência da espécie, e viria a revelar-se um das maiores contribuições para o origem da linguagem (neurônios espelho) e o desenvolvimento da cognição humana ${ }^{2,6,20}$.

Em suas considerações, Darwin enfatizava que "o homem inventou armas, ferramentas, armadilhas, construiu jangadas e embarcações, descobriu a arte de fazer o fogo. Essas diversas invenções, que o tornaram tão preponderante quando estava no estado mais grosseiro, são resultados diretos do desenvolvimento de suas faculdades, isto é, a observação, a memória, a curiosidade, a imaginação e a razão" ${ }^{19}$.

As forças da hereditariedade e das circunstâncias se conjugam e se substituem uma à outra, para conceber uma inscrição progressiva do comportamento nas estruturas orgânicas transmissíveis. Assim, os instintos, considerados como tendências comportamentais e desejos de agir em certo sentido para determinar a direção dos atos definidos, interagem com o organismo até o desenvolvimento da atividade racional de um sujeito pensante. Essa concepção permitiu a Darwin admitir que, nos organismos superiores, os instintos poderiam ser modificados em conseqüência 
de comportamentos habituais que, no início, estariam associados a certo grau de julgamento ou de razão ${ }^{19}$.

Na história evolutiva do homem, muitas etapas do seu comportamento foram percorridas e descartadas, como a prática canibal, enquanto a fortificação dos instintos sociais foi selecionada favoravelmente, levando-o a um processo de civilização ${ }^{5,21}$.

Há 400 mil anos, quando os primatas abandonavam os mortos ao relento, mostravam incapacidade de abstrair e imaginar a existência de algo transcendental àquele corpo, como alma e espírito, contudo, lutavam para salvar a vida dos integrantes do grupo, selecionando a convivência e a cooperação como proveitosas para a perpetuação da espécie ${ }^{5,7}$.

$\mathrm{Na}$ França, dentre vários fósseis datados entre 26 e 30 mil anos, os paleontólogos encontraram o de um indivíduo que tivera escoliose, crânio assimétrico e uma perna subdesenvolvida, possivelmente portador de alguma deficiência. Essa descoberta evidenciou a existência de vestígios do processo de civilização humana, em tempos tão remotos. Ao lado desse possível deficiente, estavam dois outros indivíduos com características como: o desenvolvimento completo do idioma falado, indústria lítica mais apurada, estrutura das mãos para uma melhor destreza, práticas culturais como enterro múltiplo e evidências de aspectos ligados a rituais espirituais ${ }^{16}$.

Darwin tentou provar que a lei do mais forte modelou a história biológica e, juntamente com os efeitos do hábito, selecionou variações orgânicas vantajosas e os instintos sociais, bases de toda a moral humana, conduzindo naturalmente à regra de "fazer aos homens o que gostaria que eles lhe fizessem". A fusão evolutiva com a inteligência racional reatou o laço entre natureza e cultura, sem romper o fio da continuidade evolutiva; transformando a vantagem obtida não somente em bioló-

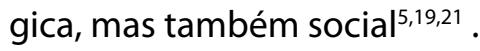

Esses comportamentos "anti-seletivos" elevaram os instintos ao progresso realizado, como: o cuidado com os doentes, a compensação das deficiências físicas e das capacidades mentais, a institucionalização do socorro e da ajuda e as intervenções sociais em favor dos mais deserdados. A elevação dos instintos a sentimentos tornou-se a chave da antropologia de Darwin: "a seleção na- tural seleciona a civilização, que se opõe à seleção natural" ${ }^{\prime \prime 2}, 20$.

\section{Fisioterapia e Locomoção: aquisições das habilidades para o controle dos movimen- tos}

Ao recordar as atividades que compõem a rotina diária, nota-se, entre as faixas etárias, diferenças individuais que determinam a ordem, a importância dos eventos e as maneiras peculiares de cada ser executar suas tarefas. Enquanto o adulto saudável mostra-se capaz de realizar múltiplas tarefas simultaneamente, a criança, em pleno desenvolvimento neuropsicomotor, formula idéias de como alcançar seus objetos. Ambos, adulto ou criança, para satisfazer seus desejos e necessidades momentâneas, precisam planejar a seqüência das ações, executá-las e, caso se depararem com possíveis tentativas frustradas, modificá-las ${ }^{9,10,22}$.

A aquisição do controle cefálico no bebê sadio decorre do sinergismo muscular entre a cabeça e cintura escapular o que favorece iniciar o alcance e a manipulação. As informações sensoriais provenientes da periferia chegam ao sistema nervoso para compor a percepção, no reconhecimento e na localização dos objetos, auxiliar na adequação do tônus, na aquisição da força muscular e coordenação necessárias para ajustar os movimentos de preensão manual às diferentes características dos objetos. Para tanto, o acoplamento entre a escápula, o braço e o tronco afetam tanto a velocidade quanto o trajeto da mão, $0^{93,24}$.

O desenvolvimento intelectual e afetivo normal de um bebê participa da construção das suas habilidades motoras, assim como inversamente, explorar o meio ambiente e realizar diversas atividades contribui para sua formação cognitiva e comportamental. A integração com os pais atua como motivação para a adaptação ao meio e induz os bebês a reproduzirem comportamentos de superação para que sejam aceitos e reconhecidos como parte integrante de um grupo, como por exemplo: vencer a frustração de não alcançar os objetos desejados e não transportá-los simultaneamente enquanto se locomovem ${ }^{9,10,17,23}$. O caminho percorrido no processo de aprendizagem inicia-se com a compreensão da natureza de uma tarefa e, logo após, na elaboração mental das estratégias que possibilitem a maneira mais eficiente 
que progressivamente será capaz de reduzir os níveis de atenção endereçados para o controle postural e concentrar-se nas informações provenientes do meio ambiente e das tarefas de seu interesse $^{9,10}$.

A aquisição ou modificação dos movimentos para ação hábil individual resulta da experiência e ou da prática de atividades que despertam o interesse e a motivação individual, sendo inferido a partir do comportamento e modificando-o em longo prazo 9.23 .

O controle postural bípede consiste no prérequisito para a deambulação e refere-se ao alinhamento dos segmentos articulares necessários para manter o centro de gravidade dentro dos limites máximos da estabilidade, enquanto a interação complexa entre os sistemas músculoesquelético e neuronal envolve a percepção e a ação, para garantir a relação sincrônica entre os segmentos corporais e o ambiente ${ }^{12,25-28}$. A manutenção do controle postural recebe a colaboração de múltiplas áreas sensoriais, como por exemplo, do sistema somatossensorial ou proprioceptivo, por meio de informações originadas nos músculos, cápsulas e outros tecidos moles. Tais informações são retransmitidas ao tronco encefálico que, por sua vez, as transmite ao cerebelo e/ou ao tálamo e este último as irradia principalmente para as áreas encefálicas somestésicas. As informações sensoriais enviadas ajudam a coordenar os movimentos dos olhos, da cabeça e do pescoço, a fim de estabilizar o sistema visual e de manter as posturas e os padrões coordenados do movimento, 9,27,29. O equilíbrio depende da interação entre sistema visual, cognitivo, vestibular, sensório-motor, então, não é visto apenas como resposta reativa ao estímulo, pois seu controle é pró-ativo, adaptativo e centralmente organizado, baseado em uma experiência anterior, a antecipação 9,24,26,29.

A organização específica dos sistemas posturais é determinada pela estimulação terapêutica dentro de tarefas funcionais e do ambiente no qual ela está sendo executada. $\mathrm{O}$ ato de percorrer um ambiente complexo ou cheio de objetos requer informações sensoriais, auxilia no controle e na adaptação do andar, desenvolve a capacidade de iniciar e terminar a marcha, para adaptá-la de maneira a evitar os obstáculos, alterar a velocidade e a direção, de acordo com as necessidades ${ }^{9,25,30}$.
O bipedalismo é adquirido durante o desenvolvimento neuropsicomotor normal e consolidado pelas posturas que o antecedem, a partir do primeiro ano de vida e aos sete anos de idade, a marcha está biomecanicamente semelhante àquela praticada por adultos ${ }^{6,16,18,25-28}$.

O início do andar representa muito mais do que uma queda simples e, a partir de um a três passos, é possível atingir-se uma velocidade estável, que poderá variar dependendo dos propósitos relacionados à marcha pretendida pelo indivíduo. Todas as diferentes formas de locomoção destacam-se pelo rítmo e automatismo dos movimentos gerados por circuitos neurais, conhecidos como centros geradores de padrões rítmicos (GCP). No homem, esses circuitos estão situados na medula espinal e regiões supramedulares (córtex sensório-motor, cerebelo e núcleos da base), que são responsáveis pelo comando de ativação seqüencial dos músculos, durante a marcha.

Esses circuitos formam centros oscilatórios que, em cada ciclo, ativam motoneurônios extensores e inibem, simultaneamente, os motoneurônios flexores de um membro inferior, ocorrendo o contrário no outro membro. No decorrer da marcha, os GCP da região medular ativam os movimentos flexoextensores alternados e estereotipados que são modulados pelos ajustes finos das regiões supramedulares. Tais movimentos podem ser modificados pela vontade do indivíduo ou pelas irregularidades do ambiente 9,13,14,29-31.

Embora a locomoção seja um ato voluntário, uma vez iniciada não exige um direcionamento consciente nas condições normais, a ponto de não notarmos nossas passadas e sobrepormos a esses movimentos todos os tipos de ações que requeiram maior ou menor nível de atenção, como: andar e carregar uma sacola ou um copo com água, falar com um amigo, e até mesmo ler um livro, 12,13,30,31. Os estudos cinemáticos sugerem uma semelhança entre as estratégias de movimentos adotadas por todos. No entanto, parece haver uma grande variedade de padrões de ativação muscular, utilizados por indivíduos sem alterações locomotoras para empregar a versatilidade funcional, que permite aos membros inferiores se acomodarem prontamente a degraus, mudanças de superfícies e obstáculos no caminho da progressão 9,24,30,31. 
Qualquer eventualidade, como os problemas genéticos, ou outros, que possam alterar o funcionamento da vida do indivíduo, resultam na interferência dos planos iniciais e convencionais. Um mecanismo de idéias e adaptações é desencadeado na tentativa de preservar ou resgatar a velocidade da dinâmica do movimento e a capacidade de locomoção sobre os pés, associadas à solução dos problemas com as mãos ${ }^{9,10,30,31}$. Fisioterapia contemporânea e a evolução funcional

Na prática clínica, as descobertas científicas que geram tanto o aperfeiçoamento tecnológico quanto o medicamentoso, contribuem para a minimização das seqüelas e o aumento da sobrevida dos pacientes com qualidade. Para tanto, os profissionais da área da saúde tem se empenhado em elaborar terapias funcionais projetadas em intervenções sistêmicas das afecções cognitivas e sensório-motoras individuais ${ }^{9,10,26}$.

Os motivos que levam um indivíduo a recorrer à fisioterapia devem concentrar-se, direta ou indiretamente, no deslocamento sem auxiliares, dentro de uma velocidade esperada, quase sempre com alvos para atingir, com eficiência e qualidade em busca do bem-estar. Assim, aperfeiçoar o controle motor e otimizar a recuperação funcional significa integrar nos programas de exercícios, atividades vivenciadas em ambientes enriquecidos e executados em cadeia cinética aberta e fecha$\mathrm{da}^{10,24,31,32}$. Nas atividades em cadeia cinética fechada ocorre suporte de peso no segmento distal e contração de ambos os grupos musculares agonistas e antagonistas, ou seja, a maioria dos movimentos funcionais. Quando o pé ou a mão não estão em contato com o solo ou outra superfície qualquer, caracteriza a atividade em cadeia cinética aberta, que produz cisalhamento maior da superfície articular dentro de único plano de movimento e estimula grupos musculares isolados sem suporte de peso nos segmentos distais ${ }^{9}$.A avaliação integral tende a auxiliar o fisioterapeuta a elaborar a ordem e a sequência da sua abordagem, bem como dosar a intensidade da aplicação dos seus fundamentos e recursos no tratamento individualizado. A motivação encontrada nas atividades funcionais dentro do contexto de vida do paciente tende a auxiliar o fisioterapeuta a despertar os potenciais ocultos e extrair a performance máxima de cada indivíduo, pela exclusão do olhar simplista que atribui somente ao aparelho locomotor as limitações dos movimentos corporais ${ }^{9,10,26}$.
A abordagem fisioterápica contemporânea incentiva o treino da funcionalidade e a modulação dos graus de liberdade no controle postural, além de propor atividades em ambientes enriquecidos com transeuntes e barreiras arquitetônicas. Assim, possibilita o desvio da atenção do paciente para a modificação do andar em antecipação às ameaças desestabilizadoras do equilíbrio, e a manipular os objetos enquanto caminha sobre rampas, calçadas, desníveis, em condições visuais reduzidas ou dicas visuais móveis. O treinamento que inclui as tarefas mais complexas, pode facilitar aos pacientes, o domínio das tarefas menos complexas $^{9,10,23,24,29-32}$.

No entanto, tão importante quanto elaborar o programa de atividades, é observar as tendências comportamentais de cada paciente bem como as variações de seu humor, ansioso ou apático, para compatibilizar a abordagem proposta às particularidades de cada comportamento. A eficiência das instruções verbais agregadas ao reforçamento pode ser o modo mais prático de interferir na motivação e no comportamento do indivíduo, mas a comunicação não verbal, ou seja, aquela realizada através da postura, dos gestos e da expressão facial; inflexão da voz, sequência, ritmo e cadência das próprias palavras, é um recurso igualmente valioso para favorecer o alcance das metas e consolidar a relação entre o terapeuta e o paciente, inclusive naqueles que apresentam distúrbios de linguagem ${ }^{9,10,24,26,33,34}$.

O enfoque terapêutico para a marcha bípede em diferentes pisos, em associação com as ações que envolvem os membros superiores, seja em cadeia cinética aberta ou fechada, consiste em caminhos realistas almejados no processo de reabilitação individual. $\mathrm{O}$ investimento nas pesquisas e nas observações das práticas clínicas auxiliam na demarcação dos escopos da reabilitação para a aquisição de alvos terapêuticos cada vez mais ousados $^{9,10,24,26,30-32}$.

\section{CONSIDERAÇÕES FINAIS}

Os antropóides percorreram os caminhos tortuosos da evolução, e a partir da marcha bípede, imprimiram na sua anatomia, as resultantes do desenvolvimento das pressões seletivas ambientais e sociais para se sobreporem como espécie dominante. 
A modificação do comportamento necessária para a sobrevivência e manutenção da espécie em ambiente adverso, proporcionou ao homem condições de ampliar as suas faculdades e habilidades manuais, como o planejamento da caçada, a convivência em grupo e a sofisticação dos sistemas de comunicação.

Atualmente, o homem interage com o mundo circundante e espera, igualmente, que os programas propostos para recuperação da sua performance física desafiem os sistemas músculo esquelético e neural à regeneração.

\section{REFERÊNCIAS}

1..Jordan B. O espetáculo da evolução: sexualidade, origem da vida, DNA e clonagem. Rio de Janeiro: Jorge Zahar, 2005, 132p. 2.Foley RA. Os humanos antes da humanidade: uma perspectiva evolucionista. São Paulo: Unesp, 1998, 294p.

3.Cremo MA, Thompson RL. A história secreta da raça humana. São Paulo: Aleph Publicações e Assessoria Pedagógica, 2004, 408p.

4.Povinelli DJ, Preuss TM. Theory of mind: Evolutionary history of a cognitive specialization. Trend Neurosci 1995;18:418-24.

5.Darwin C. The descent of man and selection in relation to sex. Nova lorque: Random House, 1871, 467p.

6.Morris D. O animal humano: Uma perspectiva pessoal da Espécie humana. Lisboa: Gradiva- Publicações, 1996, 223p.

7.Darwin C. On the origin of the species by means of natural selection, or the preservation of facoured races in the struggle for life. Londres: Murray J, 1859, 502p.

8.Winston R. Instinto humano. São Paulo: Globo, 2006, 431p.

9.Shumway-Cook A, Woollacott MH. Controle Motor: teorias e aplicações práticas. 2a ed. São Paulo: Manole, 2003, p.289-377. 10.Silva CB, Varise EM. Traumatismo crânio encefálico: Abordagem fisioterapêutica pela escala cognitiva. Fisioterapia: aspectos clínicos e práticos da reabilitação. São Paulo: Artes Médicas. 2005, p.309-35.

11.Page SP, Gater DR, Bach-y-Rita P. Reconsidering the motor recovery plateau in stroke. Arch Phys Med Rehabil 2004;85:1377-81.

12.Dietz V, Duysens J. Significance of load receptor input during locomotion: a review. Gait and Posture 2000;11:102-10.

13.Lent R. Cem bilhões de neurônios: conceitos fundamentais de neurociência. São Paulo: Atheneu 2005, p.133-270. 14.Mackay-Lyons M. Central Pattern Generation of Locomotion: A review of the evidence. Phys Ther 2002;82:69-83.

15. Rose M. Espectro de Darwin: a teoria da evolução e suas implicações no mundo moderno. Rio de Janeiro: Jorge Zahar, 2000, 264p.
Os princípios da abordagem contemporânea propõem aos fisioterapeutas a utilização de estratégias de comunicação verbal e não verbal que interferem favoravelmente nas atividades que estimulem as habilidades individuais; os aspectos da funcionalidade e afetividade para o reaprendizado e o retreinamento do controle motor dos pacientes, em cadeia cinética aberta e ou fechada, para tentar resgatar a marcha bípede associada às ações proposicionais em ambientes enriquecidos.
16.Teoria da evolução (Endereço na Internet). Brasil: Faculdade de Biologia da UNESP (última atualização: 12/2007; citado em: 05/2009). Disponível em: http://www.nossosancestrais. blogspot.com

17.Stanford C. Como nos tornamos bípedes. Rio de Janeiro: Elsevier, 2004, 256p.

18.Dilts RB. A estratégia da Genialidade. Volume I. São Paulo: Summus Editorial, 1998, 277p.

19.Lenay C. Darwin. São Paulo: Estação Liberdade Marques, 2004, 188p.

20.Gallese V, Goldman A. Mirror neurons and the simulation theory of mindreading. Trend Cog Sci 1998;2:493-501.

21.Tort P. Darwin e a ciência da evolução. Rio de Janeiro: Objetiva, 2004, 159p.

22.Fukuyama DJ. Biologia Evolutiva. 2a edição. Ribeirão Preto: Sociedade Brasileira de Genética, 1993, 228p.

23. Mohr JD. Management of the trunk in adult hemiplegia: the Bobath concept. In: Herdman SJ, editor. Topics in neurology. Alexandria: American Physical Therapy Association, 1990, $1-12$.

24.Michaelsen SM, Dannenbaum R, Levin MF. Task-Specific training with trunk restraint on arm recovery in stroke: Randomized control trial. Stroke 2006;37:186-92.

25.Perry J. Analise de marcha. Volume 3. São Paulo: Manole, 2005, 225p.

26.Camargo CIA. Traumatismo crânio-encefálico: níveis cognitivos e prognóstico de reabilitação. In: Capovilla FC, Gonçalves MJ, Macedo EC. Tecnologia em (Re) Habilitação Cognitiva, uma perspectiva multidisciplinar. São Paulo: EDUNISC: 1998, 416p.

27.Rosa GM, Souza WC, Pinto LD, Gaban GA, Serafim AD. Análise da influência do estresse no equilíbrio postural. Fisioter Bras 2004;5:50-4.

28.Walters RL, Mulroy S. The energy expenditure of normal and pathologic gait. Gait and Posture 1999;9:207-31. 
29.Kandel ER, Schwartz JH, Jessel TM. Reflexos espinhais. In: Kandel ER. Fundamentos da neurociência e do comportamento. $4^{\text {a }}$ ed. São Paulo: Manole, 1997, p.413-22.

30.Shumway-Cook A, Patla A, Stewart S, Ferrucci L, Ciol M, Guralnik J. Environmental demands associated with community mobility in older adults with and without mobility disabilities. Phys Ther 2002;82:670-81.

31.Madeira AE, Cruz LCA, Oliveira CB, Varise EM. Teste de equilíbrio aplicado em pacientes com AVE em ambiente aberto e fechado. Arq Neuropsiquiatr 2007;65(Suppl 2):31.
32.Taylor D, Stretton CM, Mudge S, Garret N. Does clinic-measured gait speed differ from gait speed measured in the community in people with stroke? Clin Rehabil 2006;20:438-42. 33.Silva AS, Banaco RA. Investigação dos efeitos do reforçamento, na sessão terapêutica, sobre três classes de respostas verbais dos clientes. Rev Bras Terap Comportam Cog 2000;2:123-36.

34.Watzlavick P, Behavian JH. Pragmática da Comunicação Humana. 14a edição. Sao Paulo: Ed. Cultrix, 2004, 262p. 